\title{
Mechanical properties of jute fabric reinforced thermoplastic moulded by high-speed processing using electromagnetic induction
}

\author{
K. Tanaka ${ }^{1}$, T. Katsura ${ }^{1}$, Y. Kinoshita ${ }^{1}$, T. Katayama ${ }^{1}$ \\ \& K. Uno ${ }^{2}$ \\ ${ }^{I}$ Department of Mechanical Engineering, Doshisha University, Japan \\ ${ }^{2}$ Marubeni Co., Ltd., Japan
}

\begin{abstract}
Fibre reinforced thermoplastic (FRTP) has high performances of specific strength, specific rigidity and impact resistance. For conventional FRTP, glass fibre or carbon fibre is used for the reinforcement and polypropylene (PP) or polyamide (PA) for the matrix. These materials, however, are difficult to dispose of and a combination of natural fibre and biodegradable resin have been considered as easily degradable materials in the natural environment. Jute is one of the most superior natural fibre materials due to its low cost, high levels of production, high specific strength and ease of renewal. However, jute fibre reinforced thermoplastic moulded by the traditional hot press method requires considerable time and expense.

In this study, an advanced manufacturing process of a composite based on jute and PLA (JFRTP) moulded by a high-speed processing of composite materials using electromagnetic induction was proposed. The system allows heating of the mould surface instantaneously therefore this system can reduce production cycle times, which leads to a reduction in the manufacturing cost of composite parts. The influence of moulding conditions on the impregnation and the mechanical properties of JFRTP are discussed.
\end{abstract}

Keywords: green-composite, natural fibre, jute fibre, PLA, JFRTP, non-woven fabric, electromagnetic induction. 


\section{Introduction}

The world's industries have been concerning about disposal of plastics since the 1990s [1]. Conventional fibre reinforced plastics cause considerable problems with respect to reuse or recycling after the end of the products' lifetime, because most FRP use thermoset plastics for the matrix. It is necessary to solve the problem of the large environmental burden in the disposal of FRP.

Biodegradable polymers have been the subject of research and development in recent years. Green-composite, which means natural fibre reinforced biodegradable polymers, has received a lot of attention as it is easily degradable in the natural environment [2-4].

Some advantages associated to the use of natural fibres as reinforcement in thermoplastics are biodegradability and high specific properties [5]. Natural fibres, such as bamboo, jute, kenaf, flax, hemp, and ramie, are used as reinforcement in composite structures. Jute is one of the superior materials due to its low cost, high level of production and high specific strength.

Polylactic acid (PLA) is biodegradable, as it is derived from $100 \%$ renewable resources, such as corn and potato. This polymer works well for the matrix of the green-composites, due to its high strength, rigidity, melting point and productivity compared with other biodegradable resins [6]. Despite the above advantages of the materials forming green-composites, a manufacturing process for thermo plastics has not yet been established and a novel manufacturing process should be developed.

In this study, an advanced manufacturing process of composite based on jute and PLA (JFRTP) moulded by a high-speed processing of composite materials by electromagnetic induction was proposed.

The IH system allows heating of the mould surface instantaneously. There is no need to preheat the mould and the material before placing it in the mould. This system also can reduce production cycle times, which leads to a reduction in cost for manufacturing the composite parts [7]. Jute fabric reinforced thermoplastics (JFRTP) using jute plain woven fabrics with PLA non-woven fabrics were moulded, and the aim of the present work is to investigate the mechanical properties of JFRTP to estimate the jute fibre degradation by conditioning in high temperature.

\section{Materials and experimental procedure}

\subsection{Material and moulding process}

Jute plain fabric and non-woven fabric for polylactic acid (PLA) were used in this study. The weight per unit area of jute and PLA are $370 \mathrm{~g} / \mathrm{m}^{2}$ and $50 \mathrm{~g} / \mathrm{m}^{2}$, respectively. They were oven-dried at $80^{\circ} \mathrm{C}$ for $5 \mathrm{~h}$ before moulding.

Test specimens were moulded by the traditional hot press method (Kohtaki precision machine Ltd., Japan) and high-speed processing using electromagnetic induction (IH system; Roctool Co. Cage System ${ }^{\circledR}$ ). Fig. 1 shows the schematic drawing of the IH system. This high-speed processing allows heating of only the 
mould surface, instantaneously. When an electrical current runs through an inductor, a magnetic field is generated. The magnetic field penetrates the mould placed inside the inductor, and creates induced currents on the mould surface. Current flow is shown in Fig. 1 (b). Since the current flow is concentrated within the mould surface, only the mould surface is heated by the Joule effect and, therefore, the heating process from $25^{\circ} \mathrm{C}$ to $190^{\circ} \mathrm{C}$ requires only 50 seconds. The principal advantage of the IH system is that the heat source is located close to the material. There is no longer any need to preheat the mould or the materials before placing them in the mould.

The moulding condition of the specimens is listed in Table 1. The fibre volume content of specimens varied from $40-60 \%$. The moulding temperature is $190^{\circ} \mathrm{C}$ and the moulding pressure is $2 \mathrm{MPa}$.

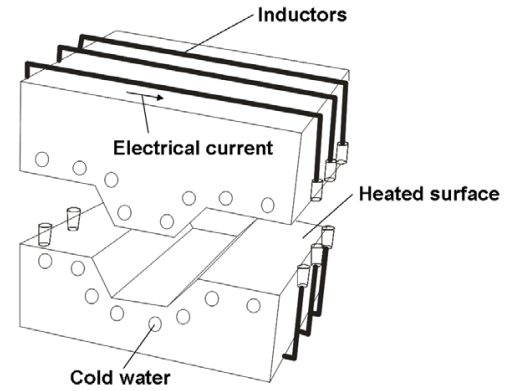

(a) Schematic drawing of IH system

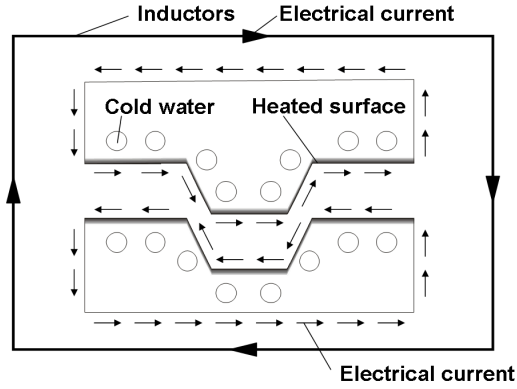

(b) Current flow of IH system

Figure 1: $\quad$ IH system (Roctool Co.; Cage system ${ }^{\circledR}$ ).

Table 1: $\quad$ Moulding condition of the specimens.

\begin{tabular}{|c|c|c|c|}
\hline Specimen & $\begin{array}{l}\text { Holding time at } \\
\text { maximum temperature }(\mathrm{s})\end{array}$ & $\mathrm{V}_{\mathrm{f}}(\%)$ & Method \\
\hline A-1 & 0 & \multirow{3}{*}{40} & \multirow{9}{*}{ IH system } \\
\hline$A-2$ & 30 & & \\
\hline A-3 & 60 & & \\
\hline B-1 & 0 & \multirow{3}{*}{50} & \\
\hline B-2 & 30 & & \\
\hline B-3 & 60 & & \\
\hline $\mathrm{C}-1$ & 0 & \multirow{3}{*}{60} & \\
\hline $\mathrm{C}-2$ & 30 & & \\
\hline $\mathrm{C}-3$ & 60 & & \\
\hline $\mathrm{D}$ & 300 & 40 & \multirow{3}{*}{ Hot press } \\
\hline $\mathrm{E}$ & 300 & 50 & \\
\hline $\mathrm{F}$ & 300 & 60 & \\
\hline
\end{tabular}




\subsection{Mechanical testing}

Tensile test specimens were prepared by following the recommended testing procedure as described in JIS-K7054. The specimens were cut out from the composites in the dimension of $200 \times 10 \mathrm{~mm}$ by a water jet. The tensile test was conducted using universal material testing machine INSTRON 5566 at the crosshead speed of $1 \mathrm{~mm} / \mathrm{min}$. For each moulding condition shown in Table 1 respectively five specimens were tested.

Three-point bending tests were also conducted, following the recommended testing procedures as described in JIS-K7017. The test specimens were cut out with a water jet. The length and width of the specimens are 60 and $15 \mathrm{~mm}$ respectively. The specimen support span was set for $40 \mathrm{~mm}$. The bending test was conducted by universal material testing machine INSTRON 5566. Load was applied to the specimen at a strain rate of $1 \mathrm{~mm} / \mathrm{min}$.

To obtain the degradation of jute fabric affected by high temperatures, single fibre tensile tests were conducted for a single jute fibre taken out from the hot pressed jute fabric using a testing machine for micro material (MMT-101NB10, Shimadzu Co., Japan). The jute fabric was hot pressed in a vacuum press machine. The pressure and heating temperatures were set for $3.0 \mathrm{MPa}$ and $190^{\circ} \mathrm{C}$. Specimens were prepared by following the recommended testing procedure as described in ASTM D3379/ JIS R7606. Polyester thin film was used for a tab and a fibre was glued to it.

Cross sections of the specimens were observed by SEM (VE-8800, product by KEYENCE) in order to investigate the resin impregnation.

\section{Result and discussion}

\subsection{Bending and tensile tests}

Fig. 2 shows the bending strength of the JFRTP. Specimen B-3 has the highest bending strength in all specimens.

Fig. 3 shows the bending strength of the JFRTP moulded by the traditional hot press method. The bending strength of specimen D was $100 \mathrm{MPa}$. The IH system required a holding time of about 30 seconds for resin impregnation, while the traditional hot press method required a holding time of 5 minutes for resin impregnation. In the case of specimen $\mathrm{C}$, when the holding time became longer than 30 seconds the bending strength decreased. This behaviour indicates the degradation of the jute fibre by high temperature during the holding time at maximum temperature.

Fig. 4 shows the tensile strength of the JFRTP. The specimens with the fibre content of $50 \%$ have highest tensile strength.

\subsection{SEM observation}

A cross section of the specimens observed by SEM is shown in Fig. 5. A lot of void was observed in specimens A-1 and B-1. In contrast with these specimens, better impregnation was observed in other specimens. The IH system required only 30 seconds for resin impregnation. 
High Performance Structures and Materials IV 215

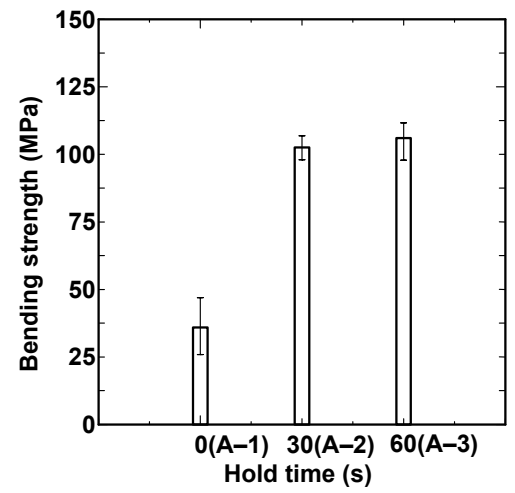

Specimen A Vf:40\%

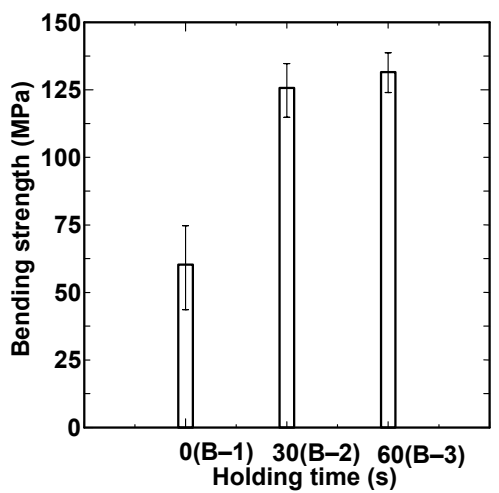

Specimen B Vf:50\%

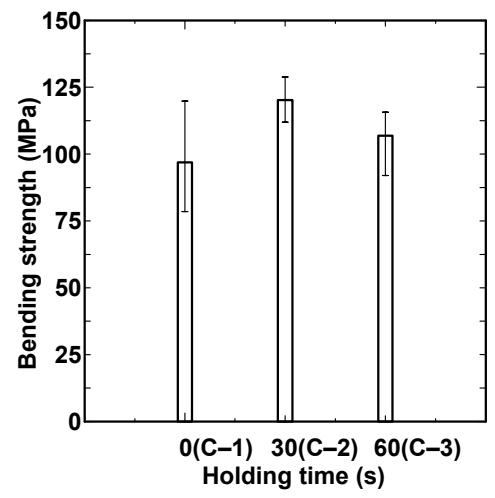

Specimen C Vf: $60 \%$

Figure 2: $\quad$ Bending strength of JFRTP.

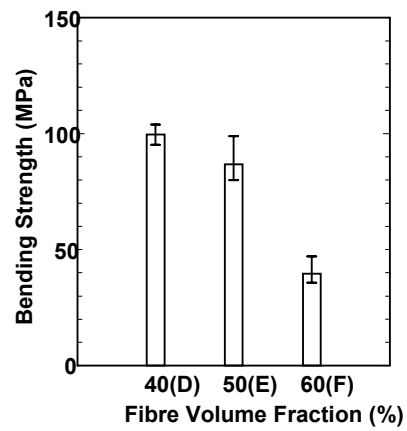

Figure 3: Bending strength of the JFRTP mould by the traditional hot press method. 


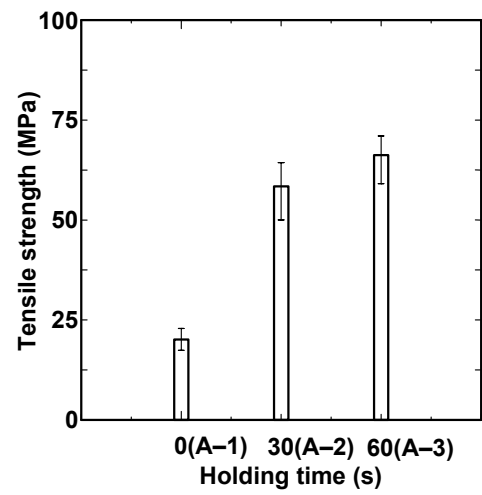

Specimen A Vf:40\%

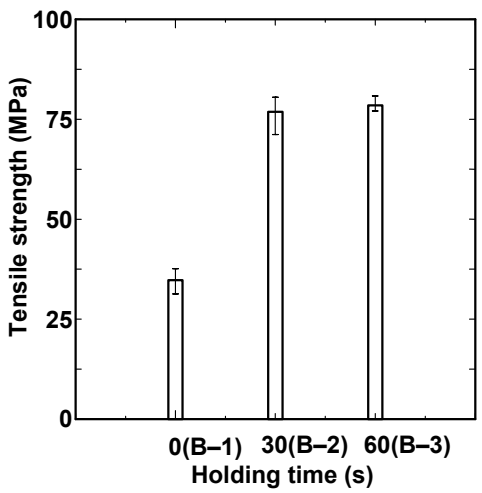

Specimen B Vf:50\%

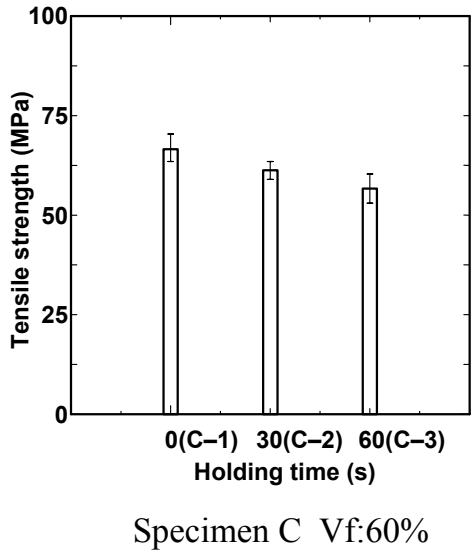

Figure 4: Tensile strength of JFRTP.

\subsection{Superior advantage of the IH system}

Fig. 6 shows the temperature history of the mould surface of the IH system. The IH system can heat only the surface of the mould, so this system required only about 50 seconds to raise the mould temperature from $25^{\circ} \mathrm{C}$ to $190^{\circ} \mathrm{C}$. The cooling of the mould can be completed in only about 180 seconds. In contrast with the $\mathrm{IH}$ system, the traditional hot press method requires 40 minutes to raise the mould temperature from $25^{\circ} \mathrm{C}$ to $190^{\circ} \mathrm{C}$. The cooling of the mould can be completed in about 160 minutes. Compared with the traditional hot press method, the IH system can reduce production cycle time drastically.

Fig. 7 shows the relationship between heating time and the tensile strength of jute fabric. The tensile strength of the specimen that was conditioned at a high temperature for 300 seconds degraded to about $23 \%$ of the original strength. Considering the degradation of this specimen at high temperature, a shorter holding time at high temperature is necessary to mould jute fibre composite. 


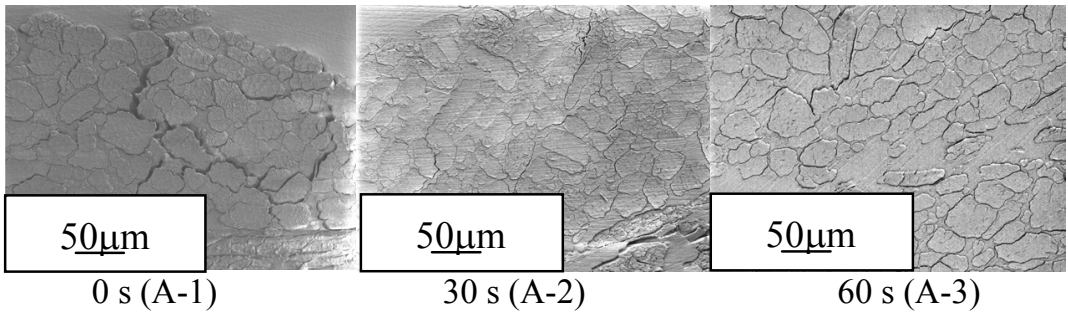

Specimen A Vf: $40 \%$

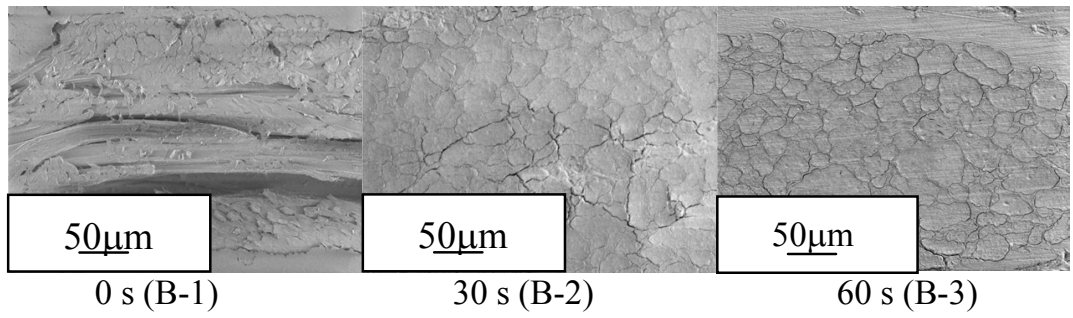

Specimen B Vf:50\%

Figure 5: $\quad$ SEM observation of the cross section.

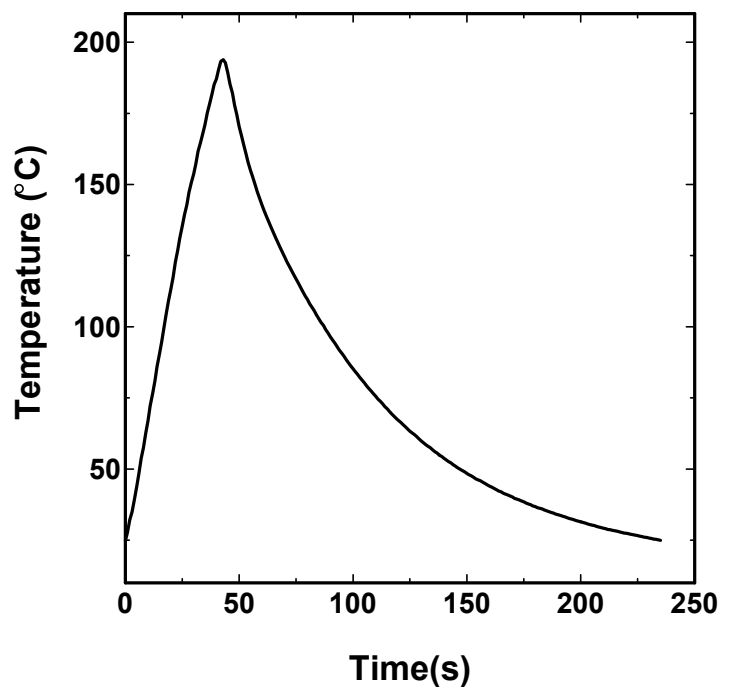

Figure 6: Temperature history of the mould surface.

Therefore the IH system had a superior advantage for moulding natural fibre reinforced plastic. The traditional hot press method requires a holding time of 5 minutes. However, the holding time of the IH system was only 30 seconds. The holding time for the traditional hot press method is longer than for the IH system 
and so the traditional hot press method causes degradation in jute fibre. The IH system is suitable for moulding natural fibre composites because it can mould them before the deterioration of the jute fibre.

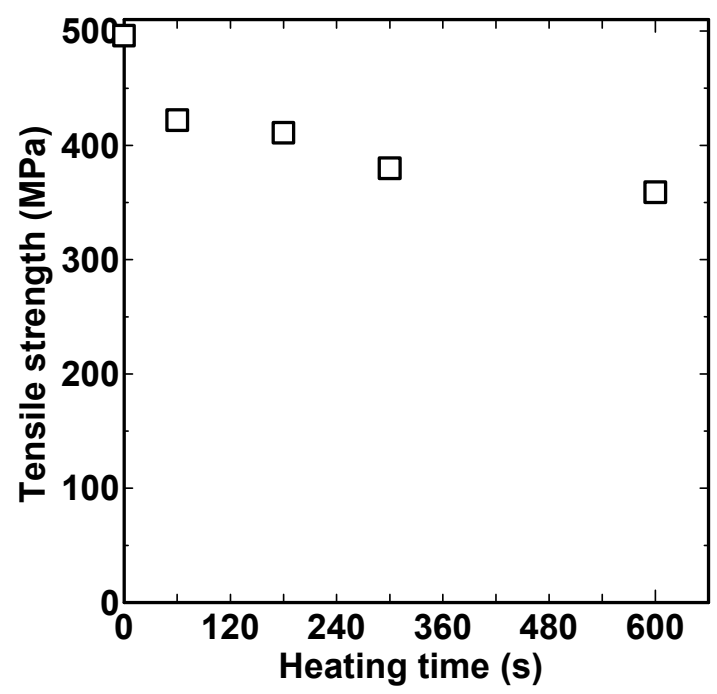

Figure 7: Relationship between heating time and tensile strength of jute fabric.

\section{Conclusion}

1. The specimen moulded by the IH system has a higher bending strength and tensile strength than that of the hot process.

2. The traditional hot press method required 50 minutes to raise the mould temperature from $25^{\circ} \mathrm{C}$ to $190^{\circ} \mathrm{C}$. In contrast with this, the $\mathrm{IH}$ system required only about 50 seconds. The IH system can heat the mould instantaneously, and reduce the production cycle time drastically.

3. To obtain a good impregnation, the $\mathrm{IH}$ system required only 30 seconds whereas the traditional hot press method required 5 minutes. The IH system required a shorter holding time at maximum temperature than the traditional hot press method. The IH system can mould JFRTP before the deterioration of the jute fibre.

\section{References}

[1] Chandra, R. Rustgi, R., Biodegradable polymers. Prog Polym Sci, 23:1273335,1998

[2] Netravali, A.N., Chabba, S., Composites get greener. Materials Today 6(4), 22-9, 2003 
[3] Mohanty, A.K., Misra, M., Drzal, L.T., Sustainable bio-composites from renewable resources: opportunities and challenges in the green materials world. Journal of Polymers and the Environment, 10(1-2), 19-26, 2002

[4] Mohanty, A.K., Misra, M., Hinrichsen, G., Biofibres, biodegradable polymers and biocomposites: an overview. Macromolecular Materials and Engineering (276-277), 1-24, 2000

[5] Netravali, A.N., Chabba, S., Composites get greener. Materials Today, 6(4), $22-9,2003$

[6] Drumright, R.E., Gruber, P.R. Henton, D.E., Polylactic acid technology. Advanced Materials, 23(12), 1841-6, 2000

[7] Alex, G., Jose, F., High-speed processing: using electromagnetic induction. JEC-composites, 94-96, 2004 